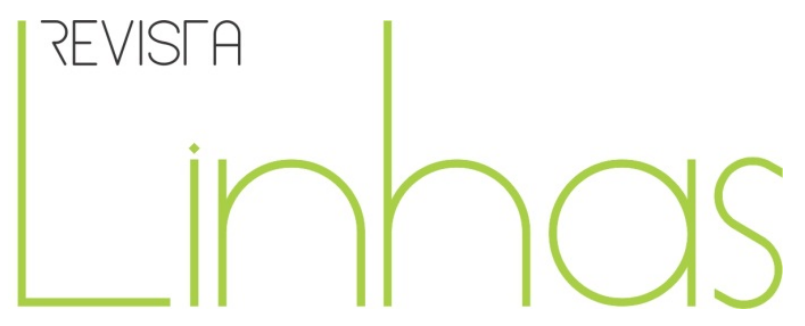

\title{
Práticas de assistência à infância no Brasil: uma abordagem histórica
}

\section{Resumo}

O texto apresenta alguns resultados parciais de duas pesquisas que se vinculam por um tema comum: a assistência à infância. Partindo dessas investigações, o texto objetiva analisar os deslocamentos históricos ocorridos nas práticas de assistência à infância no Brasil e compreender a forma como tais práticas operam sobre a população infantil. Utilizando como ferramenta teórico-metodológica a noção de governamentalidade desenvolvida por Michel Foucault, o texto é desenvolvido em quatro seções. A primeira, trata do entendimento de história que acompanhará este trabalho, mostrando que, ao olhar tanto para a emergência do sentimento de infância quanto para o surgimento de práticas de assistência às crianças, não buscamos uma origem ou um ponto embrionário de onde tudo possa ter evoluído. A segunda seção busca entender como, a partir do processo de visibilidade da infância que se engendra com a Modernidade, as crianças passam a ser alvo de tecnologias de poder. A terceira e a quarta abordam os deslocamentos ocorridos nas práticas de assistência à infância ao longo da história. Estas seções procuram mostrar essas práticas se constituem a partir de determinados regimes de verdade instituídos em cada período histórico estudado. Por fim, na última seção, apresentamos algumas possibilidades de continuidade do estudo a partir de problematizações que nos são colocadas frente ao contexto contemporâneo.

\author{
Kamila Lockmann \\ Doutoranda em Educação na \\ Universidade Federal do Rio Grande \\ do Sul. Professora do Instituto de \\ Educação da Universidade Federal do \\ Rio Grande. \\ kamila.furg@gmail.com
}

\section{Maria Renata Alonso Mota}

Doutorado em Educação pela

Universidade Federal do Rio Grande do Sul. Professor Adjunto da Universidade Federal do Rio Grande. mariarenata@terra.com.br

Palavras-chave: Infância. História. Assistência à infância.

Governamentalidade

\section{Para citar este artigo:}

LOCKMANN, Kamila; MOTA, Maria Renata Alonso. Práticas de assistência à infância no Brasil: uma abordagem histórica. Revista Linhas, Florianópolis, v. 14, n. 26 , jan./jun. 2013. p. 76 - 111. 


\title{
Making assistance to childhood in Brazil: An historical approach
}

\begin{abstract}
The text presents some partial results about two researches that can be seen together on a common theme: the assistance to childhood. From these investigations, the text goal is to analyse the historical shifts occurred on some practices of assistance to childhood in Brazil and to understand the way how these practices operate on the childhood population. Using as a theoreticalmethodological tool the notion about governmentality developed by Michel Foucault, the text is developed on four sections. First section is about how it is understood the history on this work, showing that looking for the emergence of a childhood sensing as about the urge of assistance to children practices, we don't look for a origin or a embryonic point where all would evolute. Second section looks to understand how the children become the goal of power technologies, considering the process of visibility of childhood that happens on Modernity. Third and fourth sections approach the shift that some practices made permanent in the history. These sections show that some practices are all about the age studied from some truth regime instituted on each historic moment. Finally, last section, we present some possibilities of study continuity from some problems that still don't exists on contemporary context.
\end{abstract}

Keywords: Childhood. History. Childhood assistance. Governmentality. 
Este texto apresenta alguns resultados parciais de duas pesquisas desenvolvidas no Núcleo de Estudo e Pesquisa em Educação da Infância (Nepe/Furg/CNPq, as quais discutem sobre o tema da assistência à infância e se propõe analisar os deslocamentos históricos ocorridos nas práticas de assistência à infância no Brasil, alémde compreender como operam e que efeitos produzem sobre a população infantil. Para isso, tomamos como ferramenta teórico-metodológica a noção de governamentalidade desenvolvida por Michel Foucault no decorrer de dois cursos proferidos no Collège de France: Segurança, território, população (1978) e Nascimento da biopolítica (1979). Tal noção é extremamente produtiva nas análises empreendidas nestas pesquisas, uma vez que nos permite compreender as práticas de assistência à infância como formas de governamento ${ }^{1}$ que objetivam conduzir a conduta dos sujeitos. Essa noção pode ser entendida a partir de dois sentidos distintos, mas estritamente relacionados.

O primeiro sentido atribuído à noção de governamentalidade trata de compreendê-la como uma forma de racionalidade, uma forma de ser do pensamento político, econômico e social que organiza as práticas de governo desenvolvidas em um determinado tempo e em uma determinada sociedade. "A racionalidade supõe a existência de certa lógica que opera tanto nas instituições quanto na conduta dos indivíduos e nas suas relações sociais e políticas" (MARÍN-DIAZ, 2010, p. 11). Pode-se entendê-la como certa lógica que coloca em funcionamento determinadas técnicas que objetivam conduzir as condutas dos sujeitos e das populações. Trata-se, portanto, de como pensamos a ação de governar, ou ainda, de como as tecnologias de governo são empreendidas a partir de uma racionalidade política que as coloca em operação numa época dada. De acordo com Avelino (2010. p. 22), “por racionalidades Foucault entendia

\footnotetext{
${ }^{1}$ A expressão governamento será utilizada neste texto para referir o conjunto de práticas que se disseminam pela sociedade e que têm por objetivo governar a população. Veiga-Neto (2002) aconselha que se ressuscite da língua portuguesa a palavra governamento para traduzir os textos do autor francês Michel Foucault com o "objetivo tornar mais rigoroso e mais fácil o duplo entendimento que, na perspectiva foucaultiana, é possível atribuir à palavra governo." (VEIGA-NETO, 2002, p. 17). Na língua francesa, Foucault utiliza duas palavras diferentes para se referir a governo. São elas: gouverne e gouvernement. Na língua portuguesa, Veiga-Neto (2002, p.19) sugere que se utilize Governo, com G maiúsculo, para se referir à "[...] instituição do Estado que centraliza ou toma para si a caução da ação de governar", traduzindo dessa forma gouverne por Governo. Porém, quando quisermos falar das "ações distribuídas microscopicamente pelo tecido social" (2002, p. 21), o autor sugere que utilizemos a palavra governamento, para traduzir o termo gouvernement. Este texto considerará tais orientações no uso dessas duas expressões.
} 
os conjuntos de prescrições calculadas e razoáveis que organizam instituições, distribuem espaços e regulamentam comportamentos; nesse sentido as racionalidades induzem uma série de efeitos sobre o real." Sendo assim, percebe-se que as práticas, os procedimentos e as tecnologias utilizadas para governar são produzidos e orientados por uma determinada forma de racionalidade.

Este sentido atribuído a governamentalidade nos possibilita pensar como uma racionalidade específica de nosso tempo organiza determinadas formas de conduzir as condutas dos sujeitos e das populações, possibilitando a emergência de diferentes estratégias, entre elas, as políticas de assistência à infância tão em evidência na atualidade. Talvez possamos dizer que não houve outra época na história do Brasil em que pudéssemos perceber tamanha proliferação de políticas, programas e benefícios direcionados à população infantil como na atualidade. Entre esses, podemos destacar a Ação Brasil Carinhoso, lançada em 13 de maio de 2012, com o objetivo de retirar da situação de miséria absoluta todas as famílias que tenham filhos entre zero e seis anos de idade $^{2}$. Também merecem destaque os conhecidos bolsa-gestante, bolsa-nutriz, rede cegonha, mulheres mil, além do maior e mais abrangente programa de distribuição de renda do País, o bolsa família.

O segundo entendimento de governamentalidade se refere ao estudo desenvolvido por Foucault sobre o deslocamento histórico ocorrido nas formas de conduzir as condutas dos sujeitos e da população ao longo da história do Ocidente. Tratase de uma história das artes de governar ou, como o próprio filósofo destaca, "uma história da Governamentalidade". Ao fazer essa história, Foucault mostra como, desde a Idade Média até o século XX, existiram diferentes maneiras de governar: desde uma forma de conduzir as condutas, relacionada à "pastoral das almas", até a emergência de

\footnotetext{
${ }^{2}$ A Ação Brasil Carinhoso integra o Plano Brasil sem Miséria e funciona como uma complementação do Programa Bolsa Família. A ação apresenta três eixos de atuação: a renda mínima, que repassa o valor de R\$ 70 para aquelas famílias que já recebem o bolsa família e que têm em sua composição crianças entre zero e seis anos; a ampliação do acesso de crianças a creches, que se dará por meio da construção de novas creches, vinculadas ao programa Proinfância e também por um aumento de $50 \%$ no valor por aluno repassado pelo Fundeb às creches que atenderem às crianças do Programa Bolsa Família; o terceiro eixo refere-se aos cuidados adicionais com a saúde e será desenvolvido por meio da distribuição de doses de vitamina A, ferro e medicação gratuita contra asma (Informações retiradas do Ministério de Desenvolvimento Social e Combate à Fome - MDS - http://www.mds.gov.br).
} 
um "governo político dos homens". Temos aqui, o segundo sentido atribuído à noção de governamentalidade. Como destaca Dean (1999), esse "segundo sentido é uma versão historicamente específica do primeiro", pois não trata apenas de entender a governamentalidade como uma racionalidade política, mas de se perguntar sobre "quais são os tipos de racionalidade usados nos procedimentos, nos dispositivos e nas tecnologias que a administração estatal ${ }^{3}$ emprega para governar" (ARAÚJO, 2009, p. 42) em diferentes períodos históricos.

Dessa forma, fica claro que a governamentalidade - nos dois sentidos abordados - será um conceito central nestas pesquisas. O primeiro deles - como uma racionalidade - servirá como uma grade de visibilidade que nos auxiliará a olhar as práticas de assistência à infância desenvolvidas atualmente e perceber suas vinculações com a forma de ser do pensamento político atual. Tal exercício não será desenvolvido neste artigo, uma vez que as pesquisas ainda não estão concluídas. O segundo sentido história das artes de governar — nos forneceu ferramentas importantes para compreender historicamente como surgiram as práticas de assistência à infância no Brasil, assim como as modificações ocorridas em épocas distintas. Este último entendimento será trabalhado no decorrer deste texto e nos dará suporte para discutir tanto a emergência do sentimento de infância, quanto o surgimento e os deslocamentos ocorridos nas práticas de assistência às crianças ao longo da história.

Para desenvolver tal empreendimento, organizamos o artigo da seguinte forma: na próxima seção, trataremos sobre o entendimento de história que acompanhará este trabalho, mostrando que, ao olhar tanto para a emergência do sentimento de infância quanto para o surgimento de práticas de assistência às crianças, não estamos buscando uma origem. Podemos dizer que olhamos muito mais para condições diversas e dispersas que contribuíram para a emergência e para a consolidação dessas práticas. Na segunda seção, buscamos entender como, a partir do processo de visibilidade da infância que se engendra com a Modernidade, as crianças passam a ser alvo de tecnologias de poder.

\footnotetext{
${ }^{3} \mathrm{O}$ termo administração estatal não pode ser entendido como a instituição do Estado. A autora nos lembra que Foucault não fez uma análise das instituições, nem uma análise sociológica do Estado, que o compreende como o ponto final de uma dominação sobre a sociedade civil e sobre os indivíduos. O Estado moderno, para Foucault, é visto como o resultado, o produto de práticas de governo (ARAÚJO, 2009).
} 
Neste sentido, a seção busca compreender como a infância passa a ser alvo de uma intensa produção de discursos que, ao nomeá-la, categorizá-la, ordená-la, a tornam também ponto focal de novas tecnologias de poder. Na terceira e quarta seções abordamos os deslocamentos ocorridos nas práticas de assistência à infância de forma a analisar como foram se efetivando ao longo da história. Desenvolvemos a ideia de que, até meados do século XIX, apareciam ligadas à caridade e à benemerência, sendo desenvolvidas de forma individual ou coletiva, por meio de ordens religiosas. Num segundo momento, a partir de meados do século XIX, a assistência à infância utiliza a escola como um mecanismo fundamental para agir sobre a conduta dos sujeitos, disseminando hábitos de higiene, cuidados com a saúde e formas adequadas de se comportar em sociedade. Não estamos apontando aqui um processo de substituição entre essas práticas, pois sabemos que há continuidades entre esses períodos históricos e que práticas caritativas continuam existindo até os nossos dias. No lugar de substituições, preferimos falar em ênfases diferenciadas, procurando mostrar que essas práticas se constituem, em cada período histórico que estudamos, a partir de determinados regimes de verdade instituídos em cada momento. Por fim, na última seção, apresentamos algumas possibilidades de continuidade do estudo tendo por referência problematizações que nos são colocadas frente ao contexto contemporâneo.

\section{Um olhar genealógico para a história}

Necessitamos de uma consciência histórica da situação presente.

(FOUCAULT, 2002, p. 232)

A necessidade de utilizar a história para compreender o momento presente foi tomando forma na medida em que nos deparávamos com algumas ações atualmente desenvolvidas no campo da assistência à infância. Brasil Carinhoso, Bolsa Gestante, Bolsa Nutriz, Proinfância, são alguns programas que podemos citar para mostrar a proliferação destas iniciativas na atualidade. Observando-as, fomos interpeladas por um conjunto de questionamentos acerca do tema. Por que, numa sociedade e numa época como a nossa, existe esse número considerável de programas e projetos de assistência à infância? O que 
explica tamanha expansão na atualidade? Como e por que eles surgiram em nosso país? Desde quando? O que possibilitou a constituição dessas práticas em nossa sociedade? Afinal, qual a proveniência e as condições de emergência das práticas de assistência à infância no Brasil?

Para responder a essas inquietações, pretendemos lançar um olhar genealógico sobre a emergência do sentimento de infância e sobre as práticas desenvolvidas no campo da assistência ao longo das últimas décadas. Para isso, tomamos emprestado de Nietzsche e Foucault o conceito de genealogia: um estudo histórico que se opõe à pesquisa da origem (Ursprung). A pesquisa genealógica não objetiva revelar um ponto primeiro, originário, de onde tudo evolui. Não se trata de revelar a essência de determinado objeto ou de desvendar, no passado, um ponto embrionário onde estariam alojados determinados conceitos e ideias. Segundo Foucault (1979, p.17), "procurar uma tal origem é tentar reencontrar 'o que era imediatamente', o 'aquilo mesmo' de uma imagem exatamente adequada a si; [...] é querer tirar todas as máscaras para desvendar enfim uma identidade primeira". Para o autor, a pesquisa da origem constitui-se em um projeto metafísico que busca o momento e o lugar onde as coisas se encontrariam em um estado de perfeição. Sendo assim, ele recusa a pesquisa da origem e, no lugar de acreditar em metafísica, propõe que escutemos a história, seus acasos, suas agitações, suas discórdias, surpresas, desvios e acidentes. Trata-se de compreender que a constituição de um objeto é o resultado do entrecruzamento de uma variedade de práticas e discursos que tornaram sua existência possível em um dado momento histórico. Para Foucault (1979, p. 21):

Seguir o filão complexo da proveniência é [...] manter o que se passou na dispersão que lhe é própria: é demarcar os acidentes, os ínfimos desvios - ou ao contrário as inversões completas - os erros, as falhas na apreciação, os maus cálculos que deram nascimento ao que existe e tem valor para nós; é descobrir que na raiz daquilo que nós conhecemos e daquilo que nós somos - não existe a verdade e o ser, mas a exterioridade do acidente.

Neste sentido, pode-se compreender o que pretendemos com o presente estudo, quando nos perguntamos sobre a emergência do conceito de infância e sobre a 
proveniência das políticas de assistência à infância no Brasil. Não se trata de desvendar o ponto originário e verdadeiro que marca seu único começo possível. Trata-se, no lugar disso, de buscar na história, no acontecimento mesmo da nossa vida social, as diferentes condições que possibilitaram a constituição de um conjunto de práticas vinculadas ao que chamamos de infância, com suas estratégias e seus objetos próprios.

Lançar um olhar genealógico pressupõe considerar uma série de fatos dispersos que, ao se relacionar, podem ter contribuído para a sua emergência. Isto evita uma busca incessante pela história totalitária, relatando, cronologicamente, todos os acontecimentos que se relacionam à constituição das práticas de assistência à infância em nosso país. Conforme destaca Veyne (1998, p.18), “[...] em nenhum caso, o que os historiadores chamam evento é apreendido de maneira direta e completa, mas, sempre, incompleta e lateralmente, por documentos, testemunhos, ou seja, por tekmeria, por indícios."

Dessa forma, aprendemos que toda e qualquer forma de contar uma história realiza um processo de seleção, de inclusão de alguns acontecimentos e exclusão de outros. A história nunca consegue e, nesse caso, não pretende ser totalitária. Ela seleciona, organiza produz recortes, destaca determinadas cenas e negligencia outras. Nesse processo de escolhas, optamos por realizar o seguinte exercício metodológico: tentamos compreender como, em cada momento histórico específico, a infância e as práticas de atendimento direcionadas a ela se vinculam a determinadas verdades desse tempo, produzindo modos distintos para conduzir as condutas dos sujeitos e das populações. São, portanto, formas de governo que se apresentam relacionadas a determinadas formas de manifestação da verdade. Com Foucault (2010, p. 35), aprendemos que:

[...] o exercício de poder se acompanha bem constantemente de uma manifestação de verdade entendida no sentido amplo. [...] poder-se-ia chamar a manifestação da verdade como um conjunto de procedimentos possíveis, verbais ou não, pelos quais se atualiza isso que é colocado como verdadeiro.

Sendo assim, podemos dizer que, em cada época estudada, temos uma forma de manifestação da verdade, ou seja, um conjunto de procedimentos que produzem, por 
meio de uma ritualização, algo como sendo verdadeiro e que, por isso mesmo, apresenta força constrangente. O que constrange os indivíduos não é a forma de manifestação da verdade, mas o próprio regime de verdade ao qual essa manifestação se encontra vinculada. O regime de verdade, pode ser compreendido, segundo Foucault (2010, p. 67), como "aquilo que constrange os indivíduos a um certo número de atos de verdade [...] aquilo que define, que determina a forma desses atos; é aquilo que estabelece para esses atos condições, efetuações e efeitos específicos." É o regime de verdade, pelo que ele expressa de verdadeiro, que apresenta força de constrangimento e que faz com que o indivíduo diga: "Se é verdadeiro, eu me inclinarei! Se é verdade, portanto, eu me inclino" (FOUCAULT, 2010, p. 71). Tal operação faz com que o sujeito conduza as suas ações a partir de determinados regimes de verdade. Ele passa a ser constrangido e subjetivado por esses regimes. Não se trata aqui de atos de obediência ou submissão, mas atos de verdade através dos quais mostramos nosso reconhecimento e aceitação de algo como verdadeiro.

Dessa forma, trata-se de compreender que, em cada época histórica abordada neste texto, a infância e suas práticas de atendimento aparecem vinculadas a um regime de verdade específico que constrange os indivíduos e os leva a exercer determinados atos de verdade. Lançar um olhar genealógico sobre a história nos permitiu construir um caminho possível para compreender as condições de emergência da infância moderna, assim como a proveniência das práticas de assistência à infância no Brasil. Para desenvolver este empreendimento, consideramos importante, primeiramente, discutir os diferentes entendimentos atribuídos à infância ao longo do tempo e a forma como esta foi se constituindo como etapa com características e especificidades próprias. Pensamos ser necessário desenvolver tal exercício antes de abordar o surgimento e os deslocamentos produzidos nas práticas de assistência à infância no Brasil.

\section{A infância e a sua constituição na Modernidade}

[...] a criança, tal como a percebemos atualmente, não é eterna nem natural; é uma instituição social recente ligada a práticas familiares, modos de educação e, 
conseqüentemente, a classes sociais (VARELA e AVAREZURIA, 1992, p. 69).

Ao tematizar as práticas de assistência à infância no Brasil, sentimos a necessidade de discutir, ainda que de forma breve, como a infância foi sendo percebida, que deslocamentos foram sendo operados nas formas de pensá-la e compreendê-la. Isto porque entendemos, assim como Varela e Alvarez-Uria (1992), que as formas como percebemos as crianças e a infância não são eternas nem naturais. Tentaremos mostrar, nesta seção, que a infância que conhecemos e as formas de pensá-la, que nos parecem tão naturais, são uma invenção da Modernidade. Mas, ao mesmo tempo, a invenção da infância como uma etapa de vida com especificidades próprias esteve implicada na constituição da própria Modernidade. Isso quer dizer que, numa relação de imanência, uma foi condição de possibilidade para a outra.

Ariès (1981), em seu estudo sobre a infância e a família, aponta para o fato de que, no Ocidente, a partir do Renascimento, novas formas de percepção sobre a infância são instituídas. Na Idade Média, segundo esse autor, não havia um sentimento ou consciência de infância; as crianças eram percebidas como adultos em miniatura. Tão logo passasse o período de maiores perigos e que a criança já pudesse valer por si própria, ela compartilhava do mesmo mundo que os adultos, misturando-se aos seus modos de vida. Isto quer dizer que assim que a criança passasse a conviver com os adultos, a aprendizagem, as brincadeiras, o trabalho também eram compartilhados com eles. Também os modos de vestir imitavam os modos de vestir dos adultos e não havia, nessa época, um sentimento de pudor com relação à criança no que diz respeito aos assuntos e condutas sexuais. Ainda segundo Ariès (1981), a partir do século XVII começa a se desenvolver um sentimento novo com relação à infância. Essa começa a ser percebida em suas especificidades, passando a ocupar o centro das atenções da instituição familiar, ao menos nas camadas superiores da sociedade europeia. A criança passa a ser fonte de distração e relaxamento para o adulto, sendo paparicada por aqueles que com ela convivem. Por outro lado, há também uma fonte de interesse que é externa à família e tem sua expressão representada principalmente por eclesiásticos e moralistas no século XVII que, preocupados com a disciplina e a racionalidade dos costumes, também 
voltavam suas atenções à infância. É assim que, do século XVI ao século XIX, se configura a subjetividade moderna para a infância.

É importante destacar que esse estudo realizado por Ariès (1981) não foi aceito com tranquilidade, recebendo críticas de historiadores que apontaram limites, principalmente com relação ao pioneirismo de seu trabalho, por desconsiderar em suas análises as formas de vida das crianças pobres e, ainda, pela metodologia utilizada para a comprovação de suas hipóteses ${ }^{4}$. Apesar das problematizações com relação ao estudo por ele desenvolvido, é inegável sua contribuição para a compreensão da infância percebida a partir de suas particularidades, enquanto fenômeno estreitamente ligado à Modernidade.

Bujes (2002), no livro intitulado Infância e Maquinarias, desenvolve a ideia de que os significados atribuídos à infância estão intimamente relacionados com modificações de ordem política, econômica e social que provocam formas diferenciadas de perceber o mundo. Mas numa posição um pouco diferente da assumida por Ariès (1981), a autora argumenta, ainda, que a Modernidade coloca em evidência formas específicas que possibilitam o controle e o governo das populações. Ela sustenta que o que pensamos sobre as crianças e a infância, as formas como as percebemos "são resultado de um processo de construção social, dependem de um conjunto de possibilidades que se conjugam em determinado momento da história, são organizados socialmente e sustentados por discursos nem sempre homogêneos e em perene transformação" (BUJES, 2002, p. 24).

Valendo-se da perspectiva foucaultiana, a autora mostra como da ameaça da morte passamos à exaltação da vida. A partir do século XVII, é para a vida das pessoas que se voltam as preocupações. Cria-se a necessidade, então, de uma "biopolítica da população"5 (BUJES, 2002, p. 35). Para que se efetive esse projeto de exaltação da vida

\footnotetext{
${ }^{4}$ Para uma revisão com relação às críticas ao estudo realizado por Ariès (1981), ver Kuhlman Jr. (1998), Narodowski (1999) e Heywood (2004), entre outros.

${ }^{5}$ A biopolítica da população é, segundo Foucault, um dos polos de exercício do biopoder, ou seja, esse poder que se exerce sobre a vida das pessoas. É a vida e não mais a morte o objeto e o objetivo do poder. Segundo Foucault, esse biopoder, "esse poder sobre a vida desenvolveu-se a partir do século XVII, em duas formas principais; [...] dois pólos de desenvolvimento interligados por um feixe intermediário de relações. Um dos pólos, o primeiro a ser formado, ao que parece, centrou-se no corpo como máquina: no seu
} 
instaurado na Modernidade, é necessário que se passe a dar uma atenção especial e diferenciada à infância. A partir do momento em que se passa a perceber a infância como algo individualizado, com necessidades específicas, marcadas pela diferenciação do mundo adulto, a criança se torna alvo de conhecimento. É preciso, então, conhecer mais, saber mais sobre o sujeito criança para poder exercer sobre ele procedimentos de governamento.

A criança, então, deixa de ser vista como algo divino e, também, passa a ser compreendida enquanto uma categoria social. Bujes, ao analisar as relações entre infância e poder, afirma que as crianças:

passam a se constituir como alvos do poder - pontos focais de inúmeros discursos que criam um conjunto de normas para as relações entre adultos e crianças, que ensejam sentimentos de piedade e ternura, que mobilizam experiências de toda ordem voltadas para sua educação e moralização. Elas se tornam objetos de interesse de inúmeras classes profissionais, de distintas iniciativas governamentais, de práticas especializadas, de legislação, de regimentos, de estatutos, de convenções (BUJES, 2002, p. 64).

É importante ressaltar que, na medida em que as crianças são compreendidas em suas especificidades, se tornam objeto de intervenção do Estado e também do campo científico, como destacou a autora. E, ao mesmo tempo em que elas são olhadas com mais vagar, também são descritas em minúcias por esses discursos provenientes da educação, da medicina higienista, da religião, do campo jurídico, entre outros. "Portanto, é esta perspectiva adultocêntrica de representar a infância, na qual a criança é significada como um ser em falta - imaturo, débil, desprotegido, em alguns casos necessitando de correção, em outros, de proteção - que vai justificar a necessidade de intervenção e de governo da infância" (BUJES, 2002, p. 39).

É nesse contexto que a escola - instituição que separa a criança do mundo adulto -, começa a ganhar expressão, a ponto de se tornar a instituição própria para a educação

adestramento, na ampliação de suas aptidões, na extorsão de suas forças, no crescimento paralelo de sua utilidade e docilidade, [...] - tudo isso assegurado por procedimentos de poder que caracterizam as disciplinas: uma anátomo-política do corpo humano. [...] O segundo, que se formou um pouco mais tarde, por volta da metade do século XVIII, centrou-se no corpo-espécie, no corpo transpassado pela mecânica do ser vivo e como suporte dos processos biológicos: a proliferação, os nascimentos e a mortalidade, o nível de saúde, a duração davida, a longevidade, com todas as condições que podem fazê-los variar; tais processos são assumidos mediante toda uma série de intervenções e controles reguladores: uma biopolítica da população" (FOUCAULT, 2007, p. 151-152). 
das crianças e dos jovens. Assim, na Modernidade, as crianças ganham um espaço específico não só dentro da família, mas também fora dela. Podemos dizer, então, que a invenção do sentimento moderno da infância provoca a invenção de uma pedagogia: a pedagogia moderna.

Mas, se por um lado há toda uma preocupação com a educação das crianças e dos jovens em um espaço específico - a escola -, outras tantas crianças e jovens escapam dessas formas de governamento. É nesse mesmo contexto que surge a necessidade de outras formas de intervenção e governamento da infância.

É importante destacar que não queremos afirmar que antes da Modernidade não houvesse ideias com relação à infância. Sobre essa questão, é importante destacar o estudo empreendido por Walter Kohan (2003) no livro intitulado Infância. Entre Educação e Filosofia. Na primeira parte, o autor analisa uma primeira forma de relação entre filosofia e infância, buscando em alguns dos Diálogos de Platão traços de um certo conceito de infância reproduzido no desenvolvimento da Filosofia da Educação Ocidental. Kohan (2003) desenvolve a tese de que a infância, para Platão, era parte indissociável de algo que constituiu um problema fundamental para ele, a saber: "entender, enfrentar e reverter a degradação cultural, política e social da Atenas de seu tempo" (KOHAN, 2003, p. 27).

Platão entende que a chave para explicar esse problema é educativa e, para resolvê-lo, também coloca a educação como chave fundamental. "É necessário pensar outro cuidado, outra criança, outra educação, uma experiência infantil da verdade e da justiça, que preserve e cultive o que nessas naturezas há de melhor e o ponha a serviço do bem comum" (KOHAN, 2003, p. 28). Neste sentido, Platão não tem na infância um problema filosoficamente relevante enquanto infância, em sua especificidade, mas na possibilidade de educá-la para que a pólis se torne mais justa e melhor. Kohan (2003) chama a atenção para o fato de que Platão, ao se referir às crianças, não utiliza uma palavra que seja exclusiva. Isto poderia nos levar a pensar que a infância não tinha nenhuma relevância social. Porém, de acordo com o autor, ainda que Platão não tenha utilizado uma palavra específica, isto não significa que ele não tenha pensado a respeito. 
É assim que Kohan (2003) distingue algumas marcas do pensamento platônico com relação à infância: a infância como possibilidade; a infância como inferioridade; a infância como o outro desprezado; a infância como material da política. Ainda que corramos o risco de nos tornar um tanto esquemáticas, para compreender melhor cada uma dessas marcas apresentaremos, de forma muito breve, alguns pontos relevantes com relação a cada uma delas.

A primeira marca distinguida por Kohan (2003) é a infância como pura possibilidade. Para Platão, a educação é importante durante toda a vida; porém, é ainda muito mais valorizada no momento em que o caráter do ser humano está sendo formado. Para ele, a ocupação com a educação das crianças não se dá pelo que elas são, mas pelo que elas poderão vir a ser, para que elas possam chegar à virtude plena. Neste sentido, as crianças não são associadas a características próprias e definidas, porque esses primeiros momentos estão vinculados à possibilidade que deles virão. Daí a visão de incompletude e de falta que acompanha a ideia de infância. Ainda sobre a infância como possibilidade, Kohan (2003, p. 40) comenta o seguinte:

A princípio, essa visão da infância parece extraordinariamente positiva, poderosa: dela pode devir quase qualquer coisa; dela, quase tudo pode ser. Contudo, essa potencialidade, esse ser potencial, esconde, como contrapartida, uma negatividade em ato, uma visão não-afirmativa da infância. Ela poderá ser qualquer coisa. O ser tudo no futuro esconde um não ser nada no presente. Não se trata de que as crianças já são, em estado de latência ou virtualidade, o que irá devir; na verdade, elas não têm forma alguma, são completamente sem forma, maleáveis e, enquanto tais, podemos fazer delas o que quisermos (KOHAN, 2003, p. 40).

Juntamente com essa visão de pura possibilidade, o autor apresenta outra marca presente no pensamento platônico acerca da infância, que ele denomina de inferioridade. Para Platão, a infância é uma fase da vida que pode ser associada à inferioridade em sua relação com o homem adulto. Em alguns dos textos, a infância aparece associada ao ancião; em outras, ao escravo ou à mulher. Assim, a infância é considerada como o tempo da incapacidade, das limitações e da falta de experiência. Também como alguém que é facilmente enganável, que é contraditória e inconsistente. Este modo de pensar a infância toma como modelo "o homem adulto, racional, forte, destemido, equilibrado, justo, belo, prudente, qualidades cuja ausência ou estado embrionário, incipiente, torna as crianças e 
outros grupos sociais que compartilham desse estado inferiores, na perspectiva de Platão" (KOHAN, 2003, p. 49).

A terceira marca anotada por Kohan (2003) apresenta a visão de infância presente no pensamento de Platão como o outro desprezado. Nessa marca, que tem relação com a anterior, a infância pode ser percebida como um momento que está associado ao nãoimportante, ao desprezo, ao que não tem lugar na pólis, por isso pode ser excluído. As crianças, nessa visão, são associadas à figura "de quem não compartilha uma forma de entender a filosofia, a política, a educação e por isso deve ser vencido, azotado, expulsado da pólis" (KOHAN, 2003, p.55).

Por fim, a marca da infância como material da política. Nos diversos diálogos de Platão, as discussões que envolvem infância e educação adquirem sentido em função de sua significação política. Platão se preocupa com a educação das crianças que serão, no futuro, reis que filosofem e filósofos que governem. Aqui, novamente, podemos dizer que as crianças não interessam a Platão por serem crianças, mas pelo que poderão ser os adultos que governarão a pólis. Por isso, a educação das crianças é para Platão, uma tarefa política:

As relações entre política e educação são carnais: educa-se a serviço de uma política a um só tempo em que a educação política persegue, ela mesma, fins educativos. Por isso a educação é tão decisiva para Platão, porque é sua melhor ferramenta para alcançar a pólis sonhada (KOHAN, 2003, p. 59)

Com essa breve incursão acerca das marcas da infância no pensamento de Platão empreendida por Kohan, podemos perceber que a existência de sentimentos com relação à infância precede a Modernidade. Podemos perceber deslocamentos e continuidades dos discursos da infância antiga com relação à infância moderna. Sem adotar uma perspectiva apenas continuísta ou descontinuísta da história, Kohan (2003, p. 22) pondera que as ideias de Platão com relação à infância poderiam ser consideradas apenas como "uma marca intermediária de um percurso muito mais longo de um conceito de infância semelhante". Também poderíamos pensar em termos de uma certa continuidade do pensamento platônico quando analisamos a relação entre infância e educação. É possível identificar no pensamento de Platão algumas ideias que têm sido marcas nas formas de pensar a infância em nossa tradição, como, por exemplo, a ideia de 
infância como pura possibilidade. Por outro lado, poderíamos afirmar que na Modernidade um novo sentimento de infância, novos conceitos de disciplina e dos processos de escolarização surgem de maneira intensa, de forma que poderíamos pensar que ocorre aí uma descontinuidade com relação às formas de pensar a infância na Antiguidade.

Pensar em termos de continuidades e descontinuidades talvez possa contribuir na compreensão de como foi sendo produzido o sentimento de infância que nos passou a ser familiar. É importante salientar, ainda, que, com essa breve análise de algumas marcas do pensamento de Platão com relação à infância, não significa que estejamos contrariando a tese de Ariès (1981) de que a infância é uma invenção moderna. Isso porque, como tentamos mostrar no início dessa seção, é na Modernidade que ocorre uma intensificação de ideias com relação à infância, bem como de produção de saberes e de práticas voltados a melhor conhecê-la e educá-la. Esses saberes e práticas se conjugam em uma pedagogia vista como uma ciência em que os saberes, por ela produzidos, produzem também uma forma específica de ser criança e de perceber a infância. Do mesmo modo, esses saberes possibilitam outras formas de invenção da infância, não restritas aos processos de escolarização. Daí a importância de se analisar algumas práticas no campo da assistência à infância que foram se efetivando ao longo da história do Ocidente, e é disso que tratamos na próxima seção.

\section{A assistência à infância como caridade e benemerência}

[...] são muitos os infelizes, e muitos os que na Cidade de Sam Paulo, e em Santos se encontrarão dislacerados por Animaes, quando de noite expostos sem Cautela nas Portarias das Commonidades, outros semi vivos em desamparo na rua, e só remidos por alguma mão benéfica q. os encontra (Antônio Joze da Franca e Horta, 1803). ${ }^{6}$

[O objetivo da Roda era o de] evitar-se o horror e a deshumanidade que então praticavão com alguns recém-nascidos, as ingratas e desamorosas mães, desassistindo-os de si, e considerando-as a expor as crianças em vários lugares imundos com a sombra da noite, e de quando amanhecia $o$

\footnotetext{
${ }^{6}$ Excerto da carta escrita por Antônio Joze da Franca e Horta (governador da Capitania de São Paulo), em 1803, ao vice-rei, justificando a necessidade de uma Casa dos Expostos.
} 
dia se achavão mortas, e algumas devoradas pelos cães e outros animais, com lastimoso sentimento de piedade catholica, por se perderem aquelas almas pela falta de Sacramento do Baptismo (Atas da Mesa da Santa Casa de Misericórdia de Salvador, 1726). ${ }^{7}$

Caridade. Piedade. Generosidade. Solidariedade. Benesse. Benemerência. Complacência. Misericórdia. Ajuda. Favor: esse é o quadro inicial em que as práticas de assistência à infância encontraram espaço para se desenvolver. No Brasil, até meados do século XIX, tais práticas se apresentavam como atos de caridade ao próximo e eram desenvolvidas por meio de ordens religiosas ligadas às igrejas e conventos que ofereciam não só ajuda material, mas, também, moral e espiritual. Ao compreender as práticas de assistência à infância como uma espécie de filantropia caritativa e ato de benemerência ao próximo, operamos com a ferramenta da governamentalidade, a qual nos permite perceber que tais práticas objetivam conduzir as condutas dos sujeitos por meio de determinadas verdades que fazem circular. Ou seja, trata-se de compreender que as práticas operacionalizadas em épocas distintas se vinculam a determinadas racionalidades constituídas por verdades específicas dessa época e que, ao mesmo tempo, sustentam tais verdades. Há neste período histórico um tipo muito específico de manifestação da verdade, uma verdade religiosa que se utiliza da fé cristã para agir sobre a vida dos sujeitos aqui na terra. Pode-se perceber, “[...] nessa manifestação da verdade sob a forma de subjetividade efeitos que estão para além da ordem do conhecimento, mas que são da ordem da salvação" (FOUCAULT, 2010, p. 57). É por meio da crença na salvação eterna que se torna possível exercer o poder sobre as condutas dos homens, determinando a forma como devem agir neste mundo. Foucault (2010, p.58) nos lembra que:

[...] na medida em que os homens estão mais preocupados com a sua salvação no outro mundo do que com isso que se passa aqui embaixo; na medida em que querem verdadeiramente serem salvos, eles permanecem tranquilos e é mais fácil governá-los. [...] [quanto] mais os homens estão preocupados com a sua salvação no além, mais é fácil aqui embaixo governá-los.

\footnotetext{
${ }^{7}$ Estes excertos iniciais foram retirados do estudo desenvolvido por Corazza (1998). Optamos, assim como a autora, em manter os registros com ortografia da época.
} 
É esse princípio que podemos observar neste primeiro recorte histórico. Trata-se de indexar ao exercício de poder uma verdade metafísica que promete a salvação eterna dos sujeitos quanto mais bondosos e caridosos eles se mostrarem aqui na terra. Porém, o princípio de salvação, aqui referido, não se relaciona apenas à salvação eterna. Há, também, uma espécie de salvação terrena que se manifesta pelas formas de qualificar ou melhorar a vida dos sujeitos neste mundo. Dessa forma, podemos dizer que a assistência à infância, nesse primeiro recorte histórico, funciona por meio da benemerência e da caridade ao próximo com a finalidade de salvar - neste e no outro mundo - tanto a criança pobre e abandonada, que recebe a ajuda, quanto aquele que a oferece. Temos, portanto, dois movimentos distintos, mas conectados entre si: o primeiro se refere à salvação da alma e do corpo daquele que necessita de auxílio; o segundo se centra também na salvação da alma e do corpo, porém daquele que oferece o auxílio.

Essas primeiras práticas de assistência à infância podem ser observadas a partir das santas casas de misericórdias. Segundo Mestriner (2008), as misericórdias foram a primeira e duradoura instituição de assistência no Brasil, instalando-se, primeiramente, em Santos, em 1543, e chegando a Porto Alegre em 1803. Com isso, é possível notar que as santas casas de misericórdia começaram a funcionar no Brasil já desde o primeiro século da colonização portuguesa. Podemos dizer que elas foram as únicas instituições que socorreram os pobres, indigentes e as crianças abandonadas gratuitamente por quase três séculos.

Marcílio (1998) aponta que a assistência prestada nessas instituições, que a partir do século XVII passaram a ser chamadas de rodas dos expostos ou casas dos expostos, tinha um sentido de caridade cristã, ligada às obras de misericórdia. Segundo a autora, um dos objetivos primordiais era o de não deixar os bebês sem o sacramento do batismo, de forma que suas almas fossem salvas. Outra justificativa que aponta para a existência das rodas de expostos foi o fato de ser esse, um meio eficaz para impedir o infanticídio e o aborto.

Corazza (1998) aponta que tal nomeação foi atribuída a essas instituições, pois elas ficaram responsáveis por recolher, batizar, cuidar e até mesmo educar as crianças abandonadas. No que se refere ao papel do Estado, tanto o Estado português (que 
governou o Brasil durante o período colonial, de 1500 a 1822), quanto o Estado brasileiro (no seu período monárquico, de 1822 a 1889), não se envolviam diretamente com a administração dessas instituições ou com verbas para o seu funcionamento. Mesmo com a independência do Brasil em 1822, a forma de compreender e tratar o problema das crianças abandonadas no País, pouco se modificou. Mesmo que a responsabilidade legal pelas crianças expostas devesse ser do poder público, esse sequer repassava as verbas destinadas para esse fim e quando, raramente, o fazia, era sempre insuficiente para arcar com as despesas. Isto mostra o quanto, nessa época, o Estado não assumia responsabilidades sociais; estas ficavam a cargo de instituições de caridade ou de iniciativas individuais ${ }^{8}$.

Assumir a responsabilidade pelo cuidado e criação dos expostos era uma tarefa bastante custosa para as instituições de caridade. Sobre isso, Marcílio (1997, 1998) ressalta que, durante o período colonial, o espírito de caridade da população frequentemente servia para ajudar a manter os expostos nessas instituições. De acordo com a autora, durante a época colonial era comum homens proprietários, preocupados com a salvação de suas almas, deixarem em seus testamentos legados e esmolas para as misericórdias com este fim caritativo.

Para cumprir com suas atribuições referentes ao cuidado e à criação dos expostos, as misericórdias desenvolviam uma série de rituais: inicialmente, realizavam todos os registros possíveis sobre a criança abandonada no Livro de Matrículas.

Nesse livro, anotava-se o número de entrada, sexo, cor, idade aproximada, estado de saúde, o dia, a hora o mês e o ano em que fora deixada na Roda. Apontava também o enxoval ou roupa, qualquer papel escrito, medalha ou sinal, pelos quais a criança pudesse ser identificada, se algum dia viessem buscá-la (CORAZZA, 1998, p. 108).

Após os primeiros registros, desenvolviam-se os cuidados iniciais para com a criança, cuidados que se direcionavam ao corpo e à alma infantil. Eram tratadas,

\footnotetext{
${ }^{8}$ Essas iniciativas individuais podem ser visualizadas entre os séculos XVIII e XIX, quando a prática de criar filhos alheios ou de deixar as crianças aos cuidados de famílias ricas foi amplamente difundida no Brasil. Era raro encontrar famílias que, mesmo antes de existir o estatuto da adoção, não possuíssem pelo menos um filho de criação. Para aprofundar tais discussões, sugerimos a leitura do texto "A roda do Infantil" (CORAZZA, 1998).
} 
alimentadas pelas amas-de-leite e também batizadas. Depois do batismo, muitas vezes eram entregues a uma criadeira que recebia dinheiro para se responsabilizar por sua criação, mais ou menos até os sete ou oito anos de idade, quando a criança era devolvida à Casa. Na impossibilidade de arcar com a criação dos expostos, após a sua devolução:

A roda buscava casas de famílias que pudessem receber as crianças como aprendizes - no caso dos meninos - de algum ofício ou ocupação (ferreiro, sapateiro, caixeiro, balconista etc.) e, no caso das meninas, como empregadas domésticas. Para os meninos havia ainda a possibilidade de serem enviados para as Companhias de Aprendizes Marinheiros ou de Aprendizes do Arsenal de Guerra, verdadeiras escolas profissionalizantes dos pequenos desvalidos, dentro de dura disciplina militar (MARCÍLIO, 1997, p. 73-74)

Nessa época, a educação aparecia associada às igrejas ou ordens religiosas e tinha como principal função o ensinamento de ofícios aos pobres, assim como sua educação moral e religiosa. Tratava-se, portanto, de recolher e doutrinar as crianças pobres através das instituições caritativas e beneficentes tais como albergues, casas prisões, casas da doutrina, casas de misericórdia, seminários, etc. Corazza (1998, p. 116) relata que no interior das santas casas de misericórdia havia, entre outros funcionários, uma professora responsável por ensinar as primeiras letras e as lições de costura às meninas expostas. A autora destaca que todos os fins de semestre a professora precisava dar parte "do adiantamento das expostas [...] quer quanto às lições, quer quanto à conduta na aula" ${ }^{9}$. Aqui podemos observar uma das primeiras articulações entre assistência e educação. Nesse momento, as práticas educativas eram desenvolvidas no interior das instituições de assistência à infância e vinculavam-se, sobretudo, a um ensino manual. Arantes (2011, p.182) destaca a necessidade de analisarmos com mais minúcia essas práticas de ensino vinculadas as instituições caritativas. Ela diz que:

Quando analisamos mais de perto em que consistia o ensino ministrado pela caridade, constatamos que ele não apenas era o mínimo suficiente para a incorporação da criança nos postos mais baixos da hierarquia ocupacional, como também era atravessado por subdivisões das próprias categorias de órfão, abandonados e desvalidos, como por exemplo, órfão branco e órfão de cor, filho legítimo e ilegítimo, pobre válido e inválido, criança inocente e viciosa. Ou seja, um ensino marcado pelos

\footnotetext{
${ }^{9}$ Essas informações foram retiradas, segundo Corazza, do Regimento Interno da Santa Casa de Misericórdia da Cidade de Porto Alegre, em 1882.
} 
preconceitos da época, que visava apenas a manutenção do ordenamento social.

Sendo assim, podemos notar que, para cada grupo de órfãos, eram ensinados determinados ofícios que futuramente fariam com que essas crianças ocupassem determinadas posições na sociedade, geralmente posições hierarquicamente inferiores às das demais crianças.

Torna-se interessante perceber que, nessa associação entre assistência e educação, é esta última que passa a ser introduzida no interior do espaço assistencial, ou seja, da santa casa. Trata-se de práticas educativas desenvolvidas pelas instituições de assistência à infância. São essas instituições que desenvolvem uma série de procedimentos para a formação e, principalmente, para a profissionalização das crianças abandonadas. Atualmente, e já desde a década de 1920, observamos um movimento contrário: é a assistência que passa a ser introduzida nos espaços escolares e educacionais. É a assistência que entra na escola e passa a funcionar por meio de programas e projetos variados, e não o contrário. Ao fim e ao cabo, o que é preciso ressaltar refere-se ao fato de que, já nessa época, assistência e educação tiveram algum tipo de entrelaçamento.

Sendo assim, podemos dizer que essas práticas apresentavam uma dupla função: cuidar da alma e do corpo dos expostos. Se, por um lado, eram orientadas pelo princípio da salvação divina, o qual se alcançava por meio do batismo ou das orientações espirituais; por outro lado, tais práticas também se direcionavam aos cuidados do corpo, à sua sobrevivência, à sua criação e à sua formação. Eram, portanto, práticas de salvação da alma e do corpo dos abandonados, dos desprovidos, dos pobres e dos enjeitados.

Porém essas práticas - desenvolvidas tanto pelas obras de misericórdia, quanto pela roda dos expostos - não pretendiam ajudar apenas os pobres, necessitados ou crianças abandonadas, salvando suas almas e melhorando mesmo que escassamente suas vidas terrenas. Conforme destacado anteriormente, elas objetivavam também a salvação - nesse e no outro mundo - daquele que oferecia o auxílio. Explicamos melhor: participar das ordens religiosas, nessa época, tais como as misericórdias, por exemplo, significava, por um lado, usufruir de benefícios terrenos que melhoravam as 
possibilidades de fazer bons negócios e obter vantagens junto ao governo; por outro lado, viver essa vida de acordo com princípios religiosos, exercendo o bem e ajudando os necessitados, garantiria a salvação das almas dos benfeitores, encaminhando-os à vida eterna.

Importa ressaltar que "[...] a caridade jamais teve a pretensão de erradicar a pobreza, mas viver dela, nesta e na vida eterna" (LOBO, 2008, p 295). Dessa forma, não se questionava a existência da pobreza, ela não era entendida como um problema para a sociedade, pelo contrário, era até mesmo carregada de uma positividade mística. Havia, destaca Foucault, uma espécie de glorificação da dor e do sofrimento que produzia uma salvação comum à pobreza e à caridade (FOUCAULT, 2010). Nessa época, o sofrimento gerado pela pobreza era concebido como o caminho à salvação divina, tanto para o pobre que, ao suportá-la na vida terrena, encontraria futuramente o reino dos céus, quanto para os nobres, que poderiam, exercendo sua caridade, garantir sua própria salvação.

É verdade que os corpos das crianças abandonadas nas ruas e devoradas por animais incomodavam o ordenamento e a limpeza da cidade. Porém, nesse momento, a preocupação ainda não se direcionava à vida dessas crianças, mas à limpeza da cidade e ao encaminhamento da sua alma à vida eterna. Conforme destaca Lobo (2008), a principal questão não era a vida que se perdia, mas a preocupação de evitar que uma alma se fosse sem o batismo cristão. Esse era o principal objetivo da roda - batizar as crianças expostas -, já que, quando abandonadas nas ruas, corriam o risco de morrer sem receber o sacramento do batismo. Essas práticas, obviamente, também pretendiam desenvolver um controle sobre a sociedade; porém, isso ainda não se dava no âmbito coletivo. Eram ações que se direcionavam sobre o corpo individual das crianças abandonadas, orientando-as, a partir de regras morais e ensinando-as determinados ofícios, para que pudessem se tornar úteis à sociedade e, ao mesmo tempo, evitar os perigos que elas podiam causar futuramente caso trilhassem caminhos desonrosos. Dessa forma, pode-se dizer que, mesmo funcionando no interior de um quadro religioso, principalmente cristão, essas práticas constituem-se em mecanismos de controle, tal como nos lembra Lobo (2008). Segundo a autora, o poder exercido: 
[...] pela ajuda aos necessitados e a moralização dos costumes, com a construção dos recolhimentos e as doações de dotes para moças órfãs evitando que a pobreza as empurrasse para a prostituição, foram práticas de controle que se disseminaram com a preocupação religiosa de salvação das almas (LOBO, 2008, p. 282).

Estendendo um pouco o entendimento da autora, pensamos ser possível compreender as práticas de assistência à infância, desenvolvidas nesta época por meio da caridade e da benemerência, não apenas como práticas de controle, mas como práticas de controle-pastoral. Resolvemos nomeá-las dessa forma, pois elas não são práticas de controle, tais como as que funcionam atualmente em nossa sociedade, ou que podemos encontrar posteriormente com a entrada em cena dos discursos higienistas. Estas práticas de controle-pastoral funcionam por meio dos efeitos produzidos pelas verdades divinas e religiosas, que conduzem as condutas dos sujeitos na vida terrena com a promessa da salvação eterna. Dessa forma, podemos perceber as relações que se podem estabelecer entre essas práticas de assistência à infância, que marcam esse primeiro recorte histórico, e os princípios do poder pastoral, trabalhado por Foucault. O poder pastoral, principalmente em sua vertente cristã:

[...] deu lugar a toda uma arte de conduzir, de dirigir, de guiar, de controlar, de manipular os homens, uma arte de segui-los e de empurrálos passo a passo, uma arte que tem a função de encarregar-se dos homens coletiva e individualmente ao longo de toda a vida deles e a cada passo da sua existência (FOUCAULT, 2008a, p. 218-219).

Trata-se de uma arte que regula a existência dos homens na Terra, através da promessa divina de salvação das almas. Uma arte que só funciona como controle-pastoral da vida cotidiana dos homens, porque promete conduzir suas almas piedosas pelo caminho da salvação. É porque eles almejam e creem na salvação eterna que se deixam conduzir de determinadas formas neste mundo. É porque tais sujeitos se deixam constranger por esse regime de verdade que seus atos, neste mundo, são regulados, moldados e determinados. Trata-se de um processo de convencimento que faz as pessoas se inclinarem diante de determinada verdade. Não é obediência, nem obrigação, mas um conjunto de técnicas de convencimento que agem por meio de um governo pela 
verdade. Tais ações são práticas de governo, de condução, de regulação, de controlepastoral.

\section{A assistência científica à infância}

Um deslocamento importante ocorre nas práticas de assistência à infância desenvolvidas nesse período: passou-se de uma filantropia caritativa, na qual a preocupação com a salvação das almas era prioritária, para uma filantropia higiênica, para a qual a preocupação central se direciona à vida biológica e aos efeitos que ela pode causar à sociedade. Não demorou muito para se perceber que as formas de controlepastoral, empregadas até então, se tornavam ineficientes. Era necessário criar novas táticas de governo que permitissem não apenas um controle-pastoral dos indivíduos, mas, principalmente, um controle político-biológico da população. Começa, então, a se esboçar uma nova forma de governar que possibilitava controlar a circulação dos indivíduos, seus hábitos, suas formas de agir e conviver, evitando e prevenindo a ocorrência de acidentes, desgraças, miséria e doenças.

Isto somente foi possível com a emergência dos discursos médico-higienistas meados do século XIX e a primeiras décadas do século XX. Tal fenômeno pode ser visualizado por meio da emergência do que alguns autores, tais como Zanirato (2001), Mestriner (2008), Adorno (1990), Abreu e Castro (1987), chamaram de "filantropia higiênica". A filantropia higiênica tinha por objetivo restabelecer a ordem e cuidar da preservação da vida dos sujeitos, evitando, sobretudo, o alastramento das doenças e epidemias que, na época, causavam muitas mortes. "Eram os valores de preservação da vida que se faziam anunciar na cidade" (LOBO, 2008, p. 302). É importante lembrar que não há uma substituição da filantropia caritativa pela filantropia higiênica, como se a segunda tomasse o lugar da primeira, fazendo-a desaparecer. Abreu e Castro (1987, p. 102) são bastante claros nesse sentido, quando salientam que a:

[...] filantropia, o civilismo cristão das elites e a medicina social deram-se as mãos para inaugurar um corte decisivo para com o passado da assistência social aos 'desafortunados', incentivando a introdução e prática de novas concepções pedagógico-sanitárias. 
É importante compreender que o deslocamento ocorrido nas práticas de assistência à infância está vinculado à emergência de uma nova racionalidade política que surge no Brasil entre as últimas décadas do século XIX e o início do século XX. Essa racionalidade se organiza por meio de uma verdade específica que regula as práticas de governo e produz determinadas maneiras de agir sobre os sujeitos nessa época. “Portanto, é o problema da verdade que está em jogo nas racionalidades" (FOUCAULT, 2010, p. 22). No que se refere ao momento histórico estudado, vemos surgir uma nova forma de indexar o exercício de poder à manifestação da verdade. Não se trata mais de uma verdade religiosa, como anteriormente destacado, mas uma verdade baseada em princípios científicos e racionais que pretende demonstrar, a partir de dados precisos, o que seria a realidade do Estado brasileiro e, com isso, constranger os indivíduos a agir de determinadas formas com o intuito de modificar essa realidade. Foucault, em seu curso Do governo dos Vivos, em 1980, destaca:

A ciência: ela seria uma família de jogos de verdade que obedece todos ao mesmo regime de verdade no qual o poder da verdade foi organizado de maneira que a constrição seja assegurada pelo próprio verdadeiro (FOUCAULT, 2010, p. 74).

Desse modo, podemos dizer que, com a ciência, com essa verdade científica, outras formas de governar a população emergiram e, junto com elas, novas práticas no campo da assistência à infância passaram a se organizar nesse período. As novas formas de intervenção, as novas práticas de educação e de assistência à infância só serão possíveis se as crianças passarem a ser objeto dessa ciência, isso, porque "a infância tornou-se um domínio de interesse sobre o qual se tinha vontade de saber" (BUJES, 2002, p.37). Podemos dizer, então, que a produção de saberes sobre a infância e a instituição de práticas educativas voltadas a elas estão mutuamente implicadas.

A escola moderna foi um dos cenários em que, de modo muito especial, se operou uma série de deslocamentos com relação às formas de organização dos tempos e espaços, num processo de individualização do corpo infantil, condição para a possibilidade de um maior controle e governamento das populações infantis. A individualização da infância provoca um olhar diferenciado sobre a criança, que passa a 
ser percebida por sua inocência e também por ser desprovida de razão. É, então, percebida a partir do que lhe falta, havendo necessidade de espaços específicos que a tornem sujeito de razão. Como afirma Veiga-Neto (2000), pela incompletude de sua racionalidade, cria-se a necessidade de um processo pedagógico para que possa sair do estado de menoridade.

É neste sentido que se pode afirmar que o projeto educacional firmado na Modernidade é um projeto civilizador, por estabelecer novas condutas para os sujeitos e novas maneiras de os sujeitos se organizarem socialmente.

Elias (1993-1994) estudou detalhadamente a formação de uma determinada personalidade, estabelecendo relação entre os processos de diferenciação e de integração social. Para o autor, o processo de civilização está relacionado à organização das sociedades ocidentais em Estados. Em seu estudo, “descobre que a formação da personalidade não resulta de um processo interno e natural, mas se dá em conexão com determinados processos sociais que, no caso da história ocidental, se resumem numa progressiva diferenciação das funções sociais" (apud VEIGA-NETO, 1996, p. 197). Não assumindo o sujeito civilizado como natural e transcendental, Elias (1993-1994) realiza suas análises tomando como ponto central as relações de saber e de poder em determinado momento histórico.

Argumenta que o processo de civilização vai desde uma etapa ao final da Idade Média, em que os comportamentos são regulados por pressões externas, até uma etapa em que ocorre uma interiorização das formas de regulação dos comportamentos, o que vai se configurando em uma personalidade moderna. Pode-se perceber uma mudança nas formas de condicionamento humano, tornando automáticos e autocontroláveis os comportamentos socialmente aceitos, de tal maneira que essas formas de internalização dos comportamentos são percebidas pelo indivíduo como resultado de sua própria liberdade de escolha e ação. Sobre a mudança quanto às formas civilizadas de comportamento, salienta:

Quanto mais apertada se torna a teia de interdependência em que o indivíduo está emaranhado, com o aumento da divisão de funções, maiores são os espaços sociais por onde se estende essa rede, integrando-se em unidades funcionais ou institucionais - mais 
ameaçada se torna a existência social do indivíduo que dá expressão a impulsos e emoções espontâneas, e maior a vantagem social daqueles capazes de moderar suas paixões; mais fortemente é cada indivíduo controlado, desde a tenra idade, para levar em conta os efeitos de suas próprias ações ou de outras pessoas sobre uma série inteira de elos na cadeia social. A moderação das emoções espontâneas, o controle dos sentimentos, a ampliação do espaço mental além do momento presente, levando em conta o passado e o futuro, o hábito de ligar os fatos em cadeias de causa e efeito - todos estes são distintos aspectos da mesma transformação de conduta, que necessariamente ocorre com a monopolização da violência física e a extensão das cadeias da ação e interdependência social. Ocorre uma mudança "civilizadora" do comportamento (ELIAS, 1993, p. 198).

O processo civilizador de que ele fala se dá a partir do disciplinamento e de uma individualização que produz o indivíduo moderno, em que cada um se torna objeto de si mesmo.

Podemos depreender disso o papel importante que a escola teve, e ainda tem, nesse processo civilizador, na medida em que a instituição, com seus códigos de conduta e suas estratégias disciplinares, contribui de maneira fundamental na fabricação de sujeitos autodisciplinados.

Como afirma Bujes (2002), a noção moderna de infância, que se difundiu através de discursos provenientes de diversas áreas e incorporados por outras instituições educacionais, esteve associada aos processos de institucionalização das crianças e aos novos modos de educá-la.

Conforme destacamos na seção anterior, Ariès (1981) aponta que, no processo de diferenciação que ocorre com relação às crianças, a aprendizagem, que anteriormente se dava através do convívio direto com os adultos, passa a ocorrer em um espaço específico - o colégio -, provocando, então, um longo processo de enclausuramento das crianças. A escola elementar de massas passa a ser uma das formas bastante eficazes de difundir os códigos morais e de civilidade propagados pela cultura moderna.

Não por acaso, justamente nessa época - a partir da segunda metade do século XIX -, se sente a necessidade de oferecer escolarização aos sujeitos pobres. A educação passa a ser uma das estratégias fundamentais para gerenciar os riscos produzidos pela vida em sociedade. É também a partir da escola que se objetiva homogeneizar seus 
comportamentos e infundir valores morais condizentes com a vida social. Segundo Varela e Alvarez-Uria (1992, p. 20), "a educação das classes populares e, mais concretamente, a instrução e formação sistemática de seus filhos na escola nacional, fazem parte, na segunda metade do século XIX e em princípios do século XX, das medidas gerais do bom governo".

É verdade que, muito antes do século XIX, já existiam, no Brasil, diferentes formas de organização dos processos educativos. Porém, os conhecidos colégios, albergues ou casas de doutrina, destinavam-se à educação dos nobres, ficando a classe pobre excluída desses processos. Desse modo, podemos dizer que a escola de massas, destinada ao atendimento tanto de pobres quanto de nobres, surge no Brasil em meados do século XIX, mesmo que sua abrangência ainda se mostrasse extremamente restrita. Nesse período, já é possível visualizar o desenvolvimento de um processo de inclusão, visto que a escola moderna pretendia incluir aqueles que, até então, se mantinham excluídos das iniciativas educacionais. Este projeto inclusivo tem uma intencionalidade muito clara: trazer todos os sujeitos para dentro da escola, em especial os pobres, para educá-los, civilizá-los e ensinar-lhes hábitos e costumes condizentes com uma vida social saudável e ordenada. Fazendo uso da ironia, Varela e Alvarez-Uria (1992, p. 20) dizem que os “filantropos, higienistas, reformadores sociais e educadores empenham-se em ajudar ‘desinteressadamente’ os operários” e pobres. Esse processo de escolarização das massas aparecia articulado a um projeto mais amplo de progresso da nação e de higienização da cidade. Para o sucesso desse projeto, era fundamental agir sobre a infância.

Podemos visualizar aqui, mais uma vez, a associação entre educação e assistência. Diferentemente do que na seção anterior, porém, dessa vez não é a educação nem são os educadores que entram no espaço assistencial para realizar seus trabalhos, como aconteceu nas santas casas de misericórdia, mas o contrário. Em meados do século XIX, são as práticas assistenciais que passam a funcionar no interior da escola, principalmente por meio de medidas higiênicas e sanitaristas. No livro A Higienização dos Costumes, a autora Heloísa Pimenta Rocha nos mostra essa articulação entre educação e higiene. Ela destaca: 
Eliminar as atitudes viciosas e inculcar hábitos salutares, desde a mais tenra idade. Criar um sistema fundamental de hábitos higiênicos, capaz de dominar, inconscientemente, toda a existência das crianças. Moldar, enfim, a natureza infantil, pela aquisição de hábitos que resguardassem a infância da debilidade e das moléstias. Eis as tarefas de que se deveria incumbir a escola primária, no bojo da reforma que redefiniu o eixo da política sanitária, na década de 20 (ROCHA, 2003, p. 179).

A inserção dos discursos higiênicos e sanitaristas no currículo escolar pode ser visualizada por meio de uma série de práticas que se desenvolviam, à época, no interior do espaço escolar. Eram realizadas inspeções permanentes no corpo dos sujeitos, nos seus hábitos e em suas posturas. Seus dentes, olhos, ouvidos, garganta, unhas, a forma como se vestiam, a aparência e limpeza da roupa, dos cabelos, tudo era examinado com minúcia. Após esse exame médico-pedagógico, as crianças eram ensinadas e educadas a cuidar do seu corpo e da sua higiene a fim de que não representassem um mal nem para si, nem para os outros.

Parece-nos, observando as práticas desenvolvidas nesse período histórico específico, ser possível visualizar uma primeira porta de entrada para a assistência social na instituição escolar. Ela se dá via políticas sanitaristas que proliferam fortemente na sociedade entre meados do século $\mathrm{XIX}$ e início do século $X X$. A necessidade da escolarização das massas surge em meio a esse contexto. Vê-se na educação uma forma de agir sobre o corpo infantil, estabelecendo regras de contato, moldando comportamentos, ensinando higiene a fim de que seus hábitos (comumente vistos como nocivos à salubridade da população) pudessem ser modificados, evitando o alastramento de doenças, os contágios e todos os males que se poderiam causar à vida da população. A escola de massas foi um dos mecanismos utilizados para gerenciar esses riscos.

Mas não só a escola elementar passa a ganhar centralidade nesse processo. Se formos pensar nas formas de atendimento às crianças menores de seis anos, podemos afirmar que há uma imbricação entre assistência e educação. No Brasil, as formas de atendimento às crianças pequenas estiveram inicialmente vinculadas à caridade e, posteriormente, à filantropia. ${ }^{10}$ Bujes (2002) atenta para o fato de que as primeiras

\footnotetext{
10 Para Kuhlmann Jr. (1998), a caridade assumiu diferentes significados ao longo da história, podendo referir-se ao Estado, à religião ou a um sentimento de ordem individual com relação à pobreza. Já a
} 
instituições de educação infantil surgiram, portanto, com uma marca assistencial, tal como as práticas abordadas na seção anterior, para dar conta de uma parte da população infantil em que principalmente dois fenômenos se faziam presentes: as mortes, associadas à precariedade de condições no que diz respeito a higiene, moradia, nutrição, etc., e o infanticídio.

Nesse momento histórico, as santas casas e as rodas dos expostos começam a sofrer uma série de críticas e outras instituições são reclamadas para atender aos infantis. Manuel Vitorino, homem influente ligado ao Governo, “[...] considera as Rodas de Expostos como uma afronta às leis sociais e humanas e como uma forma de perpetuação de um matadouro de inocentes, sob o pretexto de velar a desonra e amparar a miséria" Ao mesmo tempo em que critica a roda dos expostos, destaca que "para a mãe honesta, a creche é um admirável recurso" (FALEIROS, 2011, p. 37).

Podemos perceber um deslocamento importante nesse momento. Não basta apenas existir instituições que recolham as crianças, as batizem e encaminhem suas almas à vida eterna. Agora é necessário que essas instituições sejam capazes de cuidar, de prevenir, de estender a vida dessas crianças. Segundo Bujes (2002, p. 59) “a instituição, se atentarmos para o que nos diz Foucault, nasceu associada a um movimento em prol da vida ou, para utilizar suas palavras, para "fazer-viver" E nesse afã de "fazer-viver" a população infantil, novas práticas de intervenção vão sendo gestadas a partir de uma concepção de assistência científica. Todas essas práticas, desenvolvidas entre o final do século XIX e início do século XX — período denominado no Brasil como Primeira República -, inscrevem-se numa lógica que tem o intuito de fazer viver, de potencializar a vida biológica da população. Neste sentido, poderíamos dizer que elas apresentam certa conexão com o que Foucault (1999) denominou “biopolítica da espécie humana”.

Observando o desenvolvimento dessas práticas, podemos compreender a relação que se estabelece entre dois campos de ação do exercício de poder, quais sejam: o âmbito micro e o âmbito macropolítico. É preciso entender que tais práticas, ao agir sobre os sujeitos individualmente, moldando suas condutas, estão, ao mesmo tempo,

filantropia pode referir-se à iniciativa não-governamental ou à organização racional da assistência. 
prevenindo uma série de riscos que ele pode produzir à sociedade e aos fenômenos coletivos. Portanto, intervindo sobre o corpo, ou melhor, agindo sobre a dimensão micropolítica, a escola, assim como as demais instituições, está, ao mesmo tempo, gerenciando a vida coletiva da população, ou seja, agindo sobre a dimensão macropolítica. Os indivíduos são entendidos como instrumentos que possibilitam atingir o objetivo fundamental, qual seja: realizar o governamento da população no âmbito macropolítico. Foucault (2008a, p. 63) destaca que:

A população é pertinente como objetivo, e os indivíduos, as séries de indivíduos, os grupos de indivíduos, a multiplicidade de indivíduos, não vão sê-lo como objetivo. Eles o serão simplesmente como instrumento, relevo ou condição para obter algo no plano da população.

Dessa forma, é possível observar que a escola age sobre o comportamento individual do sujeito, objetivando gerenciar os efeitos indesejáveis que ele pode produzir no interior de um conjunto denominado população. É, portanto, a população que emerge como objeto e objetivo do governo. É a vida biológica da população que se torna a preocupação central dessas novas formas de governo.

\section{Para não encerrar a discussão...}

Como apontamos no início do artigo, ele pretendeu centrar suas discussões na primeira parte da investigação, lançando um olhar para os aspectos históricos de constituição das práticas de atendimentos à infância. Vemos que muitas outras coisas poderiam ter sido abordadas; nossa intenção, porém, foi apenas destacar algumas práticas de assistência à infância em cada período histórico estudado e mostrar como elas se constituem a partir de determinados regimes de verdade instituídos em cada momento. Destacamos, primeiramente, até meados do século XIX, uma forma de governar os sujeitos baseada em um controle-pastoral que objetivava a salvação da alma e seu encaminhamento para a vida eterna. Naquela época, encontrávamo-nos diante de verdades religiosas e teológicas que conduziam a vida dos sujeitos aqui na terra por meio de princípios transcendentais e regras divinas. As práticas de assistência à infância, nesse 
período, apareciam ligadas à caridade e à benemerência, sendo desenvolvidas de forma individual ou coletiva, por meio de ordens religiosas.

A partir de meados do século XIX, principalmente com o advento da Primeira República, assistimos a um processo de racionalização das artes de governar. Saberes científicos começam a ser produzidos sobre a vida biológica da população, fazendo dela objeto e objetivo de governo. A infância não escapa a esse movimento; produzem-se saberes sobre ela e se cria uma série de instituições que têm como finalidade fazer viver, qualificar e intensificar a vida da população. É a vida e não mais a morte que se torna a preocupação dos mecanismos de poder. Nesse momento, a assistência à infância utiliza a escola como mecanismo fundamental para agir sobre a conduta dos sujeitos, disseminando hábitos de higiene, cuidados com a saúde e formas adequadas de se comportar em sociedade.

Além de perceber esses deslocamentos importantes na história de constituição e de consolidação das práticas de assistência à infância no Brasil, também se percebem outras configurações produzidas na atualidade, quando se fala em assistência e educação. Vivemos um momento na história do Brasil em que se pode visualizar uma proliferação surpreendente de políticas assistenciais que têm o intuito de atingir os mais variados grupos sociais. Entre eles, obviamente, a infância assume lugar de destaque, como foi possível observar na apresentação, em maio deste ano, da Ação Brasil Carinhoso. Parece que, mais uma vez, a assistência se fortalece e prolifera em meio às políticas públicas como uma estratégia eficaz de controle e governamento das populações. Porém, não se trata apenas de um retorno, de um reaparecimento, ou de um fortalecimento dessas práticas na atualidade. Em nossa opinião, parece haver uma (re)configuração dessas práticas de assistência que se inscrevem em uma nova racionalidade, que denominamos neoliberal. Por estarem vinculadas a uma nova racionalidade política, econômica e social, elas já não são de modo algum as mesmas. É para estas novas formas de (re)configuração que gostaríamos de olhar na continuidade da pesquisa. Por que, numa época como a nossa, podemos visualizar tamanha proliferação de projetos, programas e benefícios de assistência social? De que forma , essas novas práticas se articulam com o campo da educação? Que efeitos elas produzem 
sobre a vida das populações infantis, alvo de muitos desses programas? Essas questões continuam colocando nosso pensamento em movimento, continuam nos inquietando, nos provocando e são elas que nos mobilizam para seguirmos pesquisando.

\section{Referências}

ABREU, S. F. A.; CASTRO, M. M. P. A arte de administrar a pobreza: assistência social institucionalizada em São Paulo no século XIX. In: TRONCA, Italo. Foucault Vivo. Campinas, SP: Pontes, 1987.

ADORNO, S. A gestão filantrópica da pobreza urbana. In: Revista São Paulo em Perspectiva, 4(2), abril/junho, 1990. p. 8-17.

ARANTES, E. M. M. Rostos de crianças no Brasil. In: RIZZINI, Irene; PILOTTI, Francisco (Orgs.). A arte de governar as crianças: a história das políticas sociais, da legislação e da assistência à infância no Brasil. São Paulo: Cortez, 2011.

ARAÚJO, I. L. Foucault, para além de vigiar e punir. In: Revista Filosofia: Aurora, Curitiba, v. 21, n. 28, jan./jun. 2009. p. 39-58.

ARIÈS, P. História social da criança e da família. 2. ed. Rio de Janeiro: LCT - Livros Técnicos e Científicos Editora S.A, 1981.

AVELINO, N. Apresentação: Foucault e a anarqueologia dos saberes. In: FOUCAULT, Michel. Do Governo dos Vivos: curso no Collège de France: 1979-1980: excertos. São Paulo: Centro de Cultura Social; Rio de Janeiro: Achiamé, 2010.

BUJES, M. I. E. Infância e maquinarias. 1. ed. Rio de Janeiro: DP\&A, 2002.

CORAZZA, S. A Roda do Infantil. In: Revista Educação \& Realidade. Porto Alegre. v. 23, n.1, jan./jun. 1998. p. 87-141.

DEAN, M. Governmentality: Power and rule in modern society. London: Sage, 1999, p. 927.

ELIAS, N. O processo civilizador: uma história dos costumes. Rio de Janeiro: Jorge Zahar Editor. 1994.v.1

ELIAS, N. O processo civilizador: formação do Estado e civilização. Rio de Janeiro: Jorge Zahar Editor. 1993.v. 2. 
FALEIROS, V. P. Infância e processo político no Brasil. In: RIZZINI, Irene; PILOTTI, Francisco (Orgs.). A arte de governar as crianças: a história das políticas sociais, da legislação e da assistência à infância no Brasil. São Paulo: Cortez, 2011.

FOUCAULT, M. Do Governo dos Vivos: curso no Collège de France: 1979-1980: excertos. São Paulo: Centro de Cultura Social; Rio de Janeiro: Achiamé, 2010.

. Segurança, território, população: Curso no Collège de France: 1977 - 1978. São Paulo: Martins Fontes, 2008.

. Nascimento da Biopolítica: curso no Collège de France: 1978- 1979. São Paulo: Martins Fontes, 2008a.

. A arqueologia do saber. Rio de Janeiro: Forense Universitária, 2002.

. Em Defesa da Sociedade: curso no Collège de France (1975-1976). São Paulo: Martins Fontes, 1999.

- Microfísica do Poder. (Org. e Trad.). Roberto Machado. 13. ed. Rio de Janeiro: Graal, 1979.

. História da Sexualidade I: a vontade de saber. Rio de Janeiro: Edições Graal, 2007.

HEYWOOD, C. Uma história da infância. Porto Alegre: Artes médicas, 2004.

KOHAN, Walter O. Infância. Entre educação e filosofia. Belo Horizonte: Autêntica, 2003.

KUHLMANN Jr., M. Infância e educação infantil: uma abordagem histórica. Porto Alegre: Mediação, 1998.

. O Jardim-de-Infância e a educação das crianças pobres: final do século XIX, início do século XX. In: MONARCHA, Carlos (Org.). Educação da infância brasileira: 1875-1983. Campinas, SP: Autores Associados, 2001. p. 3-30.

LOBO, L. F. Os infames da história: pobres, escravos e deficientes no Brasil. Rio de Janeiro: Lamparina, 2008.

MARCíLIO, Maria Luiza. A roda dos expostos e a criança abandonada na história do Brasil. 1726- 950. In: FREITAS, Marcos Cezar de (Org.). História social da infância no Brasil. São Paulo: Cortez, 1997. p. 51- 76.

. História social da criança abandonada. São Paulo: HUCITEC, 1998.

MARÍN-DÍAZ. Dora Lilia. Práticas de si e governamento educacional: da (com)formação do capital humano e do indivíduo bem-sucedido e feliz. Porto Alegre: UFRGS, 2010. Proposta 
de Tese. (Doutorado em Educação) - Programa de Pós-Graduação em Educação, Faculdade de Educação, Universidade Federal do Rio Grande do Sul, Porto Alegre, 2010. MESTRINER, M. L. O Estado entre a filantropia e a assistência social. São Paulo: Cortez, 2008.

NARODOWSKI, M. Después de clase: desencantos y desafíos da la escuela actual. Buenos Aires: Novedades Educativas, 1999.

ROCHA. H. H. P. A Higienização dos Costumes: Educação escolar no projeto do Instituto de Hygiene de São Paulo (1918-1925). Campinas, São Paulo: Mercado das Letras; São Paulo: Fapesp, 2003.

VARELA, J.; ALVAREZ-URÍA, F. A maquinaria escolar. In: Teoria \& Educação. Porto Alegre, n.6, 1992. p. 68-96.

VEIGA-NETO, A. Coisas do governo... In: RAGO, M.; ORLANDI, L. B. L.; VEIGA-NETO, A. (Orgs.). Imagens de Foucault e Deleuze: ressonâncias nietzschianas. Rio de Janeiro: DP\&A, 2002. P. 13-34.

- Educação e governamentalidade neoliberal: novos dispositivos, novas subjetividades. In: BRANCO, Guilherme Castelo e PORTOCARRERO, Vera (Orgs.). Retratos de Foucault. 1. ed. Rio de Janeiro: Nau, 2000.

. A Ordem das Disciplinas. 1996. Tese (Doutorado em Educação) - Programa de Pós-Graduação em Educação, Faculdade de Educação - Universidade Federal do Rio Grande do Sul - Porto Alegre.

VEYNE. P. Como se Escreve a História; Foucault revoluciona a história. Brasília: Editora Universidade de Brasília, 1998.

ZANIRATO, S. H. Las políticas de combate a La probreza em Brasil: asistencialismo y exclusión social. In: Anuario Del CEH, №1, 2001. Disponível em: http://www.cehsegreti.com.ar/archivos/FILE_00000244_1310739450.pdf Acesso em: 6 set. 2011. 
Universidade do Estado de Santa Catarina - UDESC

Programa de Pós-Graduação em Educação - PPGE

Revista Linhas

Volume 14 - Número 26 - Ano 2013

revistalinhas@gmail.com

Recebido em: 15/11/2012 Aprovado em: 03/03/2013 